\title{
Desenvolvimento e Análise das Características de Hidrogéis de Polissacarídeos para Engenharia Tecidual de Cartilagem
}

\section{Camila M. Fonseca*, Mariana H. T. Nagahara, Ângela M. Moraes.}

\section{Resumo}

Este estudo teve por meta produzir hidrogéis biopoliméricos termossensíveis injetáveis, que gelificassem na temperatura corpórea. Os biomateriais obtidos foram analisados em relação à temperatura de gelificação, pH, ângulo de contato e citotoxicidade indireta, observando-se que formulações combinando carragena, xantana, carboximetilquitosana e metilcelulose atendem de forma adequada os requisitos estabelecidos.

\section{Palavras-chave:}

Biopolímero, hidrogel termossensível, temperatura de gelificação.

\section{Introdução}

O tecido cartilaginoso apresenta grande dificuldade de regeneração devido à ausência de vascularização, de forma que desgastes típicos da idade requerem procedimentos terapêuticos avançados e invasivos ${ }^{1}$. A engenharia de tecidos é uma alternativa para este cenário, podendo prover estruturas tridimensionais que mimetizam a matriz extracelular do tecido e auxiliam em sua regeneração, sendo os hidrogéis biopoliméricos materiais promissores para essa finalidade ${ }^{2}$.

Este estudo enfocou a produção de hidrogéis termossensíveis compostos de combinações dos biopolímeros Goma Guar (GG), Glicomanana (GC), Carragena (CR), Goma Xantana (X) e Carboximetilquitosana (CMQ) com a Metilcelulose (MC) que pudessem ser injetados diretamente na lesão, por meio de procedimentos minimamente invasivos. Para a finalidade proposta, seria desejável que o material não fosse citotóxico, que gelificasse em temperatura próxima à corpórea $\left(37^{\circ} \mathrm{C}\right)$, que fosse hidrofílico e apresentasse $\mathrm{pH}$ entre 6,9 e $7,4^{3}$.

\section{Resultados e Discussão}

Inicialmente testou-se combinações de GG, GC, $\mathrm{CR}, \mathrm{X}$ e $\mathrm{CMQ}$ com a $\mathrm{MC}$ em meio aquoso, preparadas pela adição da massa correspondente do biopolímero à água na temperatura mais apropriada para cada hidrogel, adicionando posteriormente a MC sob agitação.

As formulações contendo $G G$ não apresentaram dissolução adequada e foram descontinuadas no estudo.

Analisou-se as curvas do módulo elástico ( $\left.G^{\prime}\right)$ e do módulo viscoso (G") para cada formulação por reometria, obtendo-se o gráfico característico mostrado na Figura 1, onde é observada a inversão dos módulos em uma temperatura próxima à $37^{\circ} \mathrm{C}$.

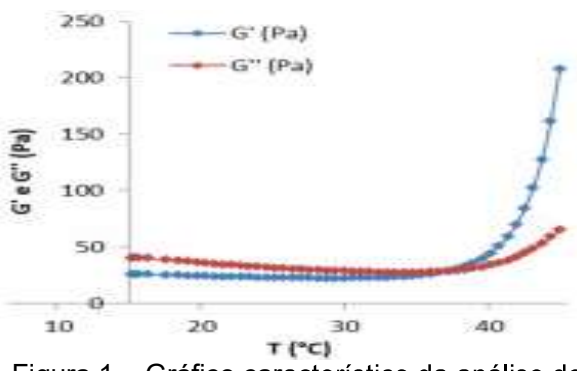

Figura 1 - Gráfico característico da análise de G' e G" para as formulações utilizadas
No entanto, todas as temperaturas de gelificação obtidas foram superiores à temperatura corpórea, de forma que se adicionou, com sucesso, glicerol $^{4}$ às formulações visando sua redução. A análise reológica e a medida de $\mathrm{pH}$ foram feitas em triplicatas para cada formulação, mas não conduziram a resultados reprodutíveis, os quais variaram aproximadamente $2{ }^{\circ} \mathrm{C} \mathrm{e}$ 1 unidade de $\mathrm{pH}$ em torno dos limites desejados.

O solvente usado para a produção dos hidrogéis foi então alterado para tampão fosfato-salina (PBS), observando-se maior reprodutibilidade entre os valores de $\mathrm{pH}$ de cada formulação, assim como gelificação abaixo da temperatura limítrofe desejada.

As formulações passaram por um processo de autoclavagem para se analisar 0 efeito da sua esterilização, verificando-se a não estabilidade da formulação com GC, que foi descartada. Realizou-se o teste de citotoxicidade indireta nas demais formulações, observando-se a não toxidade dos materiais.

Foi analisado também o ângulo de contato dos materiais mais promissores com a água, verificando-se que todas as formulações trabalhadas são hidrofílicas, com ângulos entre 50 e $70^{\circ}$, ocorrendo uma absorção deste solvente ao longo do tempo.

\section{Conclusões}

As formulações constituídas por $\mathrm{CR}, \mathrm{X}$ e $\mathrm{CMQ}$ em PBS mostraram-se as mais promissoras para a aplicação como hidrogéis termossensíveis injetáveis, pois reticulam de forma reprodutível na temperatura corpórea, têm $\mathrm{pH}$ adequado ou próximo, são hidrofílicos, esterilizáveis e não citotóxicos.

\section{Agradecimentos}

As autoras agradecem ao CNPq e à CAPES pelo financiamento da pesquisa e à Unicamp pelo apoio e pela infraestrutura disponibilizada para a sua realização.

${ }^{1}$ SOPHIA FOX, A. J.; BEDI, A.; RODEO, S. A. The basic science of articula cartilage: Structure, composition, and function. Sports Health, v. 1, p. 461468, 2009.

2PEPPAS, N. A. Biomedical applications of hydrogels handbook. New York Springer Science \& Business Media, p. 201-221, 2010

${ }^{3}$ HALL, A. C.; HORWITZ, E. R.; WILKINS, R. J. The cellular physiology of articular cartilage. Experimental Physiology, v. 81, p. 535-545, 1996.

${ }^{4}$ WESTIN, C. B; MORAES, A. M. Produção de Hidrogéis Poliméricos Injetáveis Termorresponsivos para a Engenharia de Tecidos Cartilaginosos, XXII Congresso Brasileiro de Engenharia Química, p. 3044- 3047. São Paulo Blucher, 2018. 